\title{
Histone Deacetylase Inhibitors: The Epigenetic Therapeutics That Repress Hypoxia-Inducible Factors
}

\author{
Shuyang Chen and Nianli Sang \\ Department of Biology and Graduate Program of Biological Sciences, College of Arts \& Sciences, Drexel University, \\ 3141 Chestnut Street, Stratton Hall 318, Philadelphia, PA 19104, USA \\ Correspondence should be addressed to Nianli Sang, nianli.sang@drexel.edu
}

Received 20 July 2010; Accepted 25 September 2010

Academic Editor: Minoru Yoshida

Copyright ( $\odot 2011$ S. Chen and N. Sang. This is an open access article distributed under the Creative Commons Attribution License, which permits unrestricted use, distribution, and reproduction in any medium, provided the original work is properly cited.

\begin{abstract}
Histone deacetylase inhibitors (HDACIs) have been actively explored as a new generation of chemotherapeutics for cancers, generally known as epigenetic therapeutics. Recent findings indicate that several types of HDACIs repress angiogenesis, a process essential for tumor metabolism and progression. Accumulating evidence supports that this repression is mediated by disrupting the function of hypoxia-inducible factors (HIF-1, HIF-2, and collectively, HIF), which are the master regulators of angiogenesis and cellular adaptation to hypoxia. Since HIF also regulate glucose metabolism, cell survival, microenvironment remodeling, and other alterations commonly required for tumor progression, they are considered as novel targets for cancer chemotherapy. Though the precise biochemical mechanism underlying the HDACI-triggered repression of HIF function remains unclear, potential cellular factors that may link the inhibition of deacetylase activity to the repression of HIF function have been proposed. Here we review published data that inhibitors of type I/II HDACs repress HIF function by either reducing functional HIF- $1 \alpha$ levels, or repressing HIF- $\alpha$ transactivation activity. In addition, underlying mechanisms and potential proteins involved in the repression will be discussed. A thorough understanding of HDACI-induced repression of HIF function may facilitate the development of future therapies to either repress or promote angiogenesis for cancer or chronic ischemic disorders, respectively.
\end{abstract}

\section{Introduction}

Tumors are one of the leading causes of disability and mortality in the USA and other developed countries. While many advances have been made in both basic research and clinical treatment, the development of more efficient cancer-specific therapies remains an unfinished mission. In addition to surgery and radiation therapy, chemotherapy is an important component in treating a variety of cancers, particularly for late stage, advanced cancers that are unsuitable for surgical removal. Chemotherapeutics are commonly antiproliferative compounds that preferentially kill dividing cells, rarely discriminating cancer cells, or normal dividing cells such as hematopoietic cells. Given sufficient dose and time, chemotherapeutics should be able to kill all cancer cells theoretically. However, in clinical practice, two of the major hurdles of chemotherapy are (1) tumor hypoxia, which is related to inefficient drug delivery and triggers drug resistance [1] and (2) adverse effects on normal tissues, which frequently limit the dose and duration of treatment. These two hurdles limit the efficacy of chemotherapy. To overcome these hurdles, an emerging trend in cancer therapy is to specifically target hypoxic cancer cells $[1,2]$. Indeed, hypoxia, HIF activation, and angiogenesis in solid tumors have been demonstrated by many independent studies [35]. Particularly, hypoxic and angiogenic tumors are usually resistant to traditional radiation and chemotherapy [6-10]. Blocking tumor angiogenesis has been extensively explored as a novel treatment for cancers in the past decade. The identification of HIF-function as the master regulator of angiogenesis and tumor cells adaptation to various stress conditions, including those caused by chemotherapy and radiation, provides the rationale to target HIF function as an important part in cancer therapy. Since HIF function is 
TABLE 1: Histone deacetylases: Classification and characteristics.

\begin{tabular}{|c|c|c|c|c|}
\hline Classes & & HDACs & Localization & Features \\
\hline \multirow{3}{*}{ Class I } & Ia & HDAC 1,2 & Nucleus & \multirow{3}{*}{ Related to yeast RPD3 deacetylase Zinc dependent [57] } \\
\hline & $\mathrm{Ib}$ & HDAC 3 & Nucleus \& cytoplasm & \\
\hline & Ic & HDAC 8 & Nucleus & \\
\hline \multirow{3}{*}{ Class II } & IIa & HDAC 4, 5, 7, 9 & Nucleus/cytoplasm [58] & Related to yeast HdaI Zinc-dependent $[23,24]$ \\
\hline & \multirow{2}{*}{ IIb } & HDAC6 & Cytoplasm & \\
\hline & & HDAC10 & Nucleus/cytoplasm $[59,60]$ & \\
\hline Class III & & Sirtuins (Sirt1-7) & Nucleus, cytoplasm \& mitochondria & Related to the Sir2 NAD+-dependent [25] \\
\hline Class IV & & HDAC 11 & Nucleus \& cytoplasm & Features of both classes I and II [61], Zinc independent \\
\hline
\end{tabular}

essential for both tumor progression and tissues' adaptation to chronic ischemia, it is a potential therapeutic target not only for cancer but also for chronic ischemic disorders.

In recent years, several HIF inhibitors have been identified by compound screening processes [11-13]. Interestingly and surprisingly, basic research and clinical trials have shown that HDACIs block angiogenesis and suppress tumor growth [14-16]. It has been gradually realized that these effects are at least partially mediated by repressing HIF function. Specifically, a unique phenomenon has been reported that inhibitors of class I/II HDACs, which usually stimulate transcription factors, repress the transactivation potential of both HIF- $1 \alpha$ and HIF- $2 \alpha$ [17]. Importantly, HDACIs repress HIF- $\alpha$ in all cells examined, indicating a ubiquitous mechanism [17, 18]. Although HDACIs were originally designed as epigenetic therapeutics, the effects of these compounds are generally pleiotropic. The direct molecular targets of HDACIs and the biochemical mechanisms underlying the repression of HIF function remain elusive. In this paper, we will first briefly summarize HDACs, HDACIs, and the regulatory mechanisms of HIF function. We then will focus on analyzing the potential links between protein hyperacetylation triggered by inhibitors of type I/II HDACs and its repressive effect on HIF function.

\section{Histone Deacetylases and Histone Deacetylase Inhibitors}

HDACs compass a large family of enzymes that remove the acetyl groups from $\mathrm{N}-\varepsilon$-lysines of histones [19-21]. Since the original discovery of histone acetylation, nonhistone proteins such as transcription factors or coactivators have been shown to be subjective to the same modification. Therefore, HDACs are now redefined as lysine deacetylases to more precisely reflect the fact that its substrates, acetylated lysyl residues, are not exclusive for histones [22]. Acetylation status of these proteins is usually reversibly regulated by a dynamic balance between acetyl transferases (HATs) and HDACs.

So far 18 HDACs have been identified from mammalian cells, which are classified into four classes based on their homology to yeast enzymes [23-25] (Table 1). HDAC1-3, 8 are nuclear localized class I HDACs and are most commonly associated with transcription repressive complexes known as Sin3, NuRD, CoRest (HDAC1, 2), and SMRT/NCoR
(HDAC3) [19-21, 26, 27]. Generally, Class I HDACs are considered to be repressive factors for gene expression, despite a few exceptions [28, 29]. HDAC1 is also known to inhibit the function of the phosphatase PTEN involved in cell signaling by deacetylation [30]. HDAC3 is reported to control the acetylation of p65, the subunit of NF- $\kappa \mathrm{B}$, which is a key transcription factor involved in responses to inflammation and other cellular stresses [31]. HDAC4-7, 9, 10 belong to class II [20]. HDAC4 is involved in a multiprotein transcriptional corepressor complex and is implicated in myocyte differentiation, skeletogenesis, and neuronal survival [32-35]. HDAC5 has been suggested to interact with nuclear receptor corepressors 1 and 2, which are important in the down regulation of gene expression [36]. A key role in development and pathophysiology of cardiomyocytes has been proposed for HDAC5 [37, 38]. As an exclusive member mainly functioning in the cytoplasm, HDAC6 deacetylates cytoplasmic nonhistone substrates including Hsp90 [23, 39] and $\alpha$-tubulin [40-43]. HDAC6 also binds to misfolded proteins and dynein motors, thus allowing the misfolded proteins to be physically transported to molecular chaperones and proteasomes for degradation [44]. Class III comprises of the NAD+-dependent Sirt1-7 [45-49], which has been implicated in caloric restriction, aging, neuronal degeneration, and longevity [50-52]. HDAC11, which is sometimes called class IV [53], negatively regulate interleukin 10.

HDAC inhibitors (HDACI) encompass several diverse compounds that inhibit deacetylases. Several HDACIs commonly seen in literatures are listed in Table 2, and the chemical structures of representative compounds are shown in Figure 1. Since protein acetylation in vivo is, in most cases, reversibly regulated by a dynamic balance between histone acetyl transferases (HATs) and HDACs [19-21], exposure of cells to HDACIs breaks the balance and induces hyperacetylation of proteins. Similar to enhanced HAT activity, HDACIs generally promote gene expression by elevating the acetylation status of histones, transcription factors, and coactivators. Importantly, HDACIs are anticancer compounds undergoing intensive investigation; some of them have been approved by the US Food and Drug Administration (FDA) for clinical treatment of certain types of cancer patients. Clinical and experimental data show that inhibitors of class I/II HDACs repress tumor growth and induce apoptosis. 
TABLE 2: Major HDAC inhibitors: Targets and current status in cancer chemotherapy.

\begin{tabular}{lcccc}
\hline Class & Compounds & HDACs & Status & Reference \\
\hline Aliphatic acid & Valproic acid & Class I, IIa & Phase II clinical trials & {$[62]$} \\
Benzamide & MGCD0103 & Class I, II & Phase II clinical trials & {$[63]$} \\
Cyclic peptide & FK228 & Class I, II & FDA approved for CTCL & {$[64]$} \\
& SAHA & Class I, II & FDA approved for CTCL & {$[63]$} \\
Hydroxamates & LBH589 & Class I, II & Phase II and III clinical trials & {$[23]$} \\
& Trichostatin A & Class I, II & Experimental use & {$[65,66]$} \\
Others & AR-42 & Class I, II & Started clinical trials & {$[67]$} \\
& CUDC101 & Class I, II & Started clinical trials & {$[68]$} \\
\hline
\end{tabular}

Note: Valproic acid has been in use as an anticonvulsant and mood stabilizing drug in the treatment of epilepsy and bipolar disorder.

While mainly considered as epigenetic therapeutics, HDACIs enhance the level of acetylation of nonhistone proteins as well. For example, the acetylation states of the transcription regulators such as c-Myb, E2F1, HNF-4, Ku70, NF- $\kappa \mathrm{B}$, p53, RB, Runx, Sp3, STATs, and YY1 are affected by HDACIs $[14,54]$. It is important to note that HDACIs may also affect the acetylation of cytoplasmic/mitochondrial proteins that are not directly involved in the transcriptional control of gene expression $[55,56]$.

\section{Hypoxia, Hypoxia Inducible Factors, the Oxygen Sensing Pathway, and Angiogenesis}

The oxygen-sensing pathways, which represent the canonical regulatory mechanism of HIF function, have been investigated in depth, making it possible to modulate HIF function as a novel therapy. Hypoxia-inducible factors (HIF-1, 2, 3) are heterodimeric transcription factors, each composed of a unique $\alpha$-subunit (HIF- $1 \alpha, 2 \alpha$ or $3 \alpha$ ) and a common $\beta$ subunit (HIF- $\beta$ ) shared by HIF- $\alpha$ and other transcription factors. HIF-1 and HIF-2 are the major contributors to the transcription of HIF target genes that encompass several orchestrated functional groups $[69,70]$. While regulating the expression of overlapping target genes, HIF-1 and HIF-2 have been demonstrated to possess distinctive nonredundant functions [71-73]. The overall biological effect of expression of HIF target genes is to facilitate the utilization of oxygen and other nutrients, thus inducing cellular adaptation to hypoxia, chemotherapy, and other cellular stresses $[69,70]$. Most importantly, the expression of key proangiogenic factors, such as vascular endothelial growth factor (VEGF) $[74,75]$, bFGF, and their receptors [76, 77], stimulates angiogenesis and vasculogenesis, which are fundamental processes involved in tumorigenesis, wound healing, chronic ischemic adaptation, and early embryonic development.

As heterodimeric transcription factors, HIF-1 and HIF-2 are functionally controlled by their alpha subunits (HIF- $1 \alpha$ and HIF- $2 \alpha$, resp., HIF- $\alpha$ collectively). HIF- $\alpha$ activity is controlled by two well-known mechanisms [78-80] (Figure 2). Firstly, HIF- $\alpha$ is rapidly degraded through a hydroxylationubiquitination-proteasomal system (HUPS) when oxygen is sufficient. With an adequate oxygen supply, HIF- $\alpha$ is hydroxylated at two prolyl residues in the oxygen-dependent degradation domain (ODD) by a family of prolyl hydroxylases
(PHD) [78-80]. The oxygen-facilitated hydroxylation makes HIF- $\alpha$ recognizable by VHL, an E3 ligase, for ubiquitination [78-80]. Consequently, the ubiquitinated HIF- $\alpha$ is degraded by the proteasome system $[81,82]$. Secondly, HIF- $\alpha$ activity is controlled by its transactivation potential (TAP), which is in turn controlled by its interaction with coactivator p300/CBP and other factors [83, 84]. Factor inhibiting HIF-1 (FIH), an oxygen-dependent hydroxylase, modifies an Asn residue at the carboxyl terminal activation domain (HIF- $\alpha \mathrm{CAD}$ ) and disrupts its interaction with p300/CBP $[85,86]$. In addition, HIF- $\alpha$ has an N-terminal activation domain (NAD) whose activity is also influenced by oxygen availability. Lack of oxygen (hypoxia, anoxia), a common pathophysiological condition frequently complicated with neoplastic, cardiovascular, hematologic, and respiratory disorders, represses the activity of hydroxylases and activates HIF function [78-80]. Finally, hypoxia triggered generation of reactive oxygen species by the mitochondrial electron transfer chain has been identified as a major player in the stabilization of HIF- $\alpha[87,88]$. Oxygen and oxygendependent hydroxylation-triggered events form the conventional regulatory pathways of HIF function (Figure 2), illustrating a physiological feedback.

HIF activation and the expression of HIF target genes play key roles in tumorigenesis and angiogenesis. One of the major metabolic features of tumors is that they usually demand increased oxygen, carbon, and nitrogen sources because of active biosynthesis during cell growth and proliferation [89]. Continuous growth of primary or metastatic tumors can happen only when this demand is met, usually by angiogenesis. Indeed, hypoxia and HIF-1 activation has been observed in a variety of solid human tumors [90-93], accompanied by overexpression of HIF target genes and angiogenesis. Loss of HIF- $1 \alpha$ dramatically retards solid tumor growth in vivo and is correlated with a reduced capacity to release proangiogenic factors [94-96]. Angiogenesis is defined as the formation of new blood vessels from pre-existing vessels. Neoplastic angiogenesis involves three major components [97]: (1) the tumor cells that synthesize and secret signaling molecules and growth factors (paracrine), (2) the extracellular matrix and surrounding microenvironment, and (3) the responses of endothelial and other stromal cells. It is noted that tumor-secreted signaling molecules not only function on endothelial cells, 
<smiles>CCCC(CCC)C(=O)O</smiles>

Valproic acid<smiles>Nc1ccccc1NC(=O)c1ccc(CNc2nccc(-c3cccnc3)n2)cc1</smiles>

MGCD0103

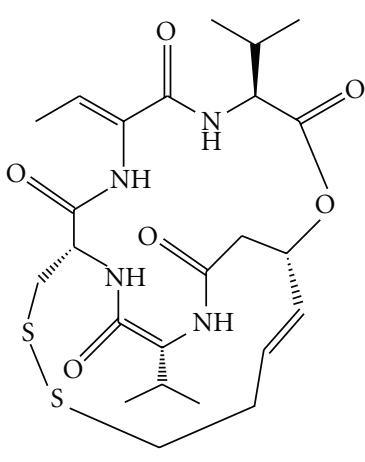

FK228<smiles>CC(/C=C/C(=O)NO)=C\[C@H](C)C(=O)c1ccc(N(C)C)cc1</smiles>

Trichostatin A

Figure 1: Chemical Structures of Representative Inhibitors of Class I/II HDACs. While structurally diverse, they share one common feature: the existence of active groups targeting the zinc-dependent catalytic sites of class I/II HDACs.

but also satisfy the growth factor requirement of tumor cells. The HIF-stimulated autocrine loop renders tumor cells independent of growth factors from other origins. Therefore, HIF-induced angiogenesis and secretion of growth factors fulfill the major needs of sustainable tumor growth, invasion, and progression. While expression of HIF- $1 \alpha$ and HIF- $2 \alpha$ has been observed in both stromal and tumor cells [71-73, 98, 99], an intrinsic or autonomous role of HIF- $2 \alpha$ in endothelial cells has been also reported [72]. HIF- $1 \alpha$ is believed to play more important roles in regulating tumor cell survival and metabolic reprogramming in response to hypoxia [94-96].

Hypoxia is not the only cause of HIF activation in tumors. In solid tumors, in addition to hypoxia, a combination of extracellular and intracellular factors (Figure 3), including growth factors, mitogenic signaling (MAPK, PI3K/Akt), activation of oncogenes, and loss of tumor suppressors (VHL, p53 and PTEN), activates HIF- $\alpha$ by acting on various points of the canonical pathways [78-80, 100-106]. Considering the complexity of signaling pathways that lead to HIF-activation in tumors, it is generally difficult to repress HIF function by repairing the aberrant canonical pathways. Furthermore, the diverse contributions of HIF target genes to metabolic reprogramming, cell survival, tumor growth, and progression make it less effective to block each effect of HIF activation. Instead, directly targeting HIF may be an ideal strategy for cancer therapy. Currently, many studies are actively exploring compounds to directly repress HIF- $\alpha$, and several HIF inhibitors have been developed [11-13].
Interestingly, some small molecular weight compounds under development for cancer therapy but not originally intended to target HIF function show good anticancer effects and antiangiogenic features. These include HDACIs [1416], heat shock protein (HSP) 90 inhibitors [107, 108], proteasome inhibitors [109-112] and microtubule inhibitors [113-115]. While these compounds are aimed at distinct cellular targets, studies have linked their antiangiogenic and antitumor effects to HIF inhibition.

\section{Histone Deacetylase Inhibitors Repress Tumor Angiogenesis and HIF Function}

Accumulating evidence suggests that inhibition of class I/II HDAC activity represses HIF function in tumor cells $[17,18$, 116-122]. The HDACIs showing anti-HIF activity generally block class I and II HDACs. While most inhibitors of class I/II HDACs are not selective for a particular deacetylase, they do not directly repress the enzymatic activity of class III HDACs (Sir2 family) [48, 49, 123]. Trichostatin A (TSA) is among several HDACIs reported to repress angiogenesis in vitro and in vivo $[118,124]$. Other HDACIs including FK228 (depsipeptide, FR901228) [120, 121], butyrate [28, 122], and LAQ82481 have been known to repress angiogenesis and expression of HIF regulated pro-angiogenic factors, such as vascular endothelial growth factor (VEGF). While HIF1 had been accepted as a major regulator of angiogenesis, the early explanations for the antiangiogenesis effects of HDACIs 


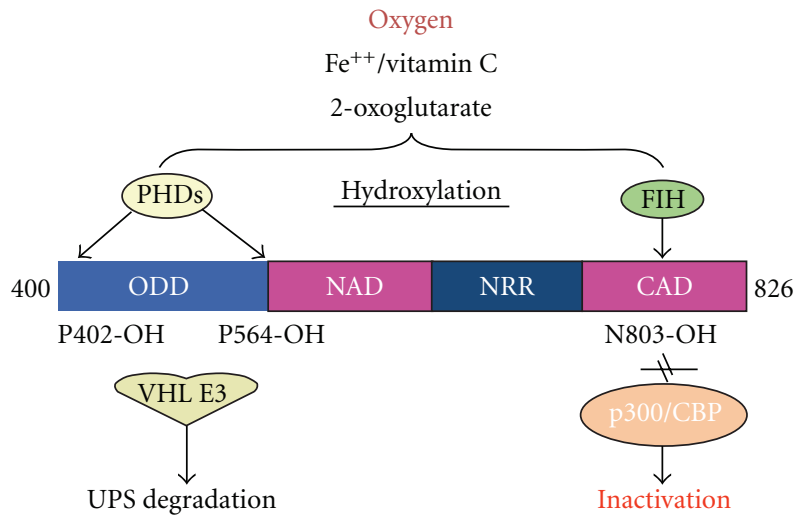

FIgure 2: Regulation of HIF- $1 \alpha$ by Oxygen-Dependent Hydroxylation. HIF function is continuously regulated by the concentration of molecular oxygen, representing an essential part of physiological feedback loop. In this feedback loop, oxygen sensing is achieved by oxygendependent hydroxylation of specific amino acid residuals of HIF- $\alpha$. Hydroxylation of two prolyl residuals leads to ubiquitination and proteasome-dependent degradation of HIF- $\alpha$. Hydroxylation of an asparagine residual located at the CAD by FIH impairs its interaction with coactivator p300 or CBP, thus repressing the transactivation activity. Note that the hydroxylation reactions require ferrous ion and ascorbic acid as cofactors, and 2-oxoglutarate as cosubstrate.

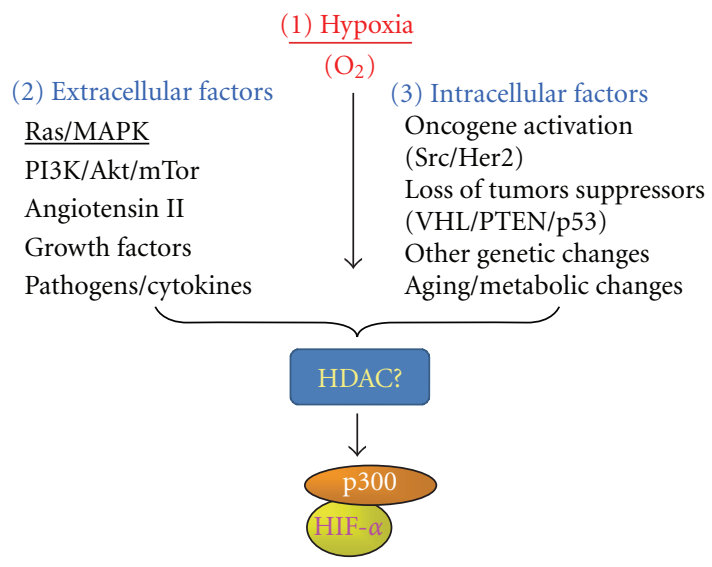

Figure 3: Multiple Signaling Pathways Regulate HIF Function and Key Determinants of the Transcription Activity of HIF-1 and HIF-2. The overall function of HIF complexes is mainly determined by protein levels of the $\alpha$-subunits (HIF- $\alpha$ ) and their interactions with p300 or CBP. Multiple signaling pathways may modulate HIF function either through acting on HIF- $\alpha$ (stability or simple posttranslational modifications) or on p300/CBP (posttranslational modifications). Eventually, the HIF- $\alpha$-p300 or HIF- $\alpha$-CBP complexes serve as the integrators of these signals and coordinate the dynamic reprogramming of gene expression. HDACs may directly interact with the HIF transcription complexes, or indirectly or functionally interact with these signaling pathways and regulate HIF function.

varied, perhaps because HDACIs have a pleiotropic nature, and multiple pathways regulate angiogenesis. Later findings suggest that HDACI-mediated repression of angiogenesis renders its effect on HIF function in tumor cells [118, 120, 124-127]. While detailed molecular and biochemical mechanisms remains unknown, several current explanations include (1) HDACI-mediated destabilization of HIF- $1 \alpha$ [18$21,26-29,40-43,48,49,53,116,118,123,124,128]$, (2) HDACI-mediated repression of the transactivation potential of the carboxyl-terminal transactivation domain of HIF$\alpha \mathrm{CAD}[17,129],(3)$ repressing DNA binding ability [120], and (4) inhibiting nuclear translocation of HIF-1 [117, 122]. Below we will focus our discussion on HDACImediated destabilization of HIF- $1 \alpha$ and HDACI-mediated repression of HIF- $\alpha$ CAD TAP, the two better supported models. We will discuss data consistent with or contrary to these views. Interested readers are referred to other proposed mechanisms including inhibiting nuclear translocation of $\operatorname{HIF}-1 \alpha[117,120,122]$.

\section{Mechanisms Underlying HDACI-Mediated Repression of HIF- $\alpha$ Transactivation Potential}

Early report suggested that TSA repressed angiogenesis by regulating VHL and p53 function, hence destabilizing HIF$1 \alpha$ [118]. Later observations show that HDACIs also repress 
the TAP of the carboxyl-transactivation domain (CAD) of both HIF- $1 \alpha$ and HIF- $2 \alpha$ [17]. This effect can be clearly demonstrated by using a recombinant HIF- $\alpha$ CAD construct fused to the DNA binding domain of the yeast GAL4 transcription factor. The protein levels of this fusion protein are not decreased by HDACIs, allowing the examination of its activity by monitoring the expression of a reporter gene [17]. All other transactivators tested in the same way, including p300, VP16, MyoD, and p53, were enhanced by HDACIs under the same conditions. The effects of HDACI on the transactivation potential have two special features that are distinct from the destabilizing effects. First, low doses of HDACIs that were not sufficient to cause HIF- $1 \alpha$ degradation were sufficient to repress HIF- $1 \alpha$ transactivation potential under both normoxic and hypoxic conditions [17]. Second, while HDACIs repress the transactivation potential of both HIF- $1 \alpha$ and HIF- $2 \alpha$, they only trigger the destabilization of HIF- $1 \alpha$, not HIF- $2 \alpha[17,18]$. Because of these two features, this mechanism may be more relevant to the antitumor effects of HDACIs than the HIF- $1 \alpha$ destabilization caused by high doses of HDACIs, because it is easier and more practical to achieve a low therapeutic dose in a clinical setting. Scientifically, this is also interesting because it shows the uniqueness of HIF- $\alpha$ among other transcription factors.

It has been well established that HIF function is determined by the protein levels and the transactivation activity of HIF- $\alpha$. HIF- $\alpha$ has two transactivation domains, the NAD and the CAD. The transactivation activity of CAD is absolutely dependent on the interaction of the CAD with either p300 or CBP. The interaction between HIF- $1 \alpha$ and p300 (or $\mathrm{CBP}$ ) requires an intact $\mathrm{CH} 1$ domain of $\mathrm{p} 300$ (or CBP). In addition, HIF- $1 \alpha$ has been reported to possess a p300/CBP $\mathrm{CH} 1$-independent transactivation activity which is also sensitive to HDACIs $[129,130]$. Because HIF- $\alpha$ CAD has been demonstrated to be absolutely dependent on p300/CBP $\mathrm{CH} 1$ [129], the p300/CBP CH1-independent mechanism might involve the NAD of HIF- $\alpha$. These reports indirectly indicate that inhibitors of class I/II HDACs also repress the transactivation activity of HIF- $\alpha$ NAD.

Because HDACIs mediate repression of HIF function in a manner independent of HIF- $\alpha$ levels, the key targets of this repression must be the HIF- $\alpha$-p300 or HIF- $\alpha$-CBP complexes (Figure 3 ). In oxygen-sensing pathway, oxygen availability regulates this interaction through FIH (Factor inhibiting HIF-1)-mediated hydroxylation of HIF- $\alpha$ CAD. However, mutation of Asn803 of HIF- $1 \alpha$ CAD did not abolish HDACI-mediated repression [17], indicating that the HDACI-mediated repression of HIF- $1 \alpha$-p 300 function is independent of either FIH or hydroxylation. The HDACImediated repression of HIF- $\alpha$ TAP is also independent of VHL [17], suggesting a mechanism distinct from the normoxic repressive pathway. Since a minimal CAD domain (HIF-1 $\alpha 786$-826) lacking the normoxic repressive region thus being constitutively active can be repressed by HDACIs [17], it is unlikely that the HDACI-mediated repression of HIF- $\alpha$ CAD involves a direct change of acetylation states of HIF- $\alpha$ [17]. HIF- $\alpha$ NAD, on the other hand, overlaps with the oxygen-dependent degradation domain and contains more than one lysyl residues. So it is possible that acetylation of any of the lysyl residues affects NAD transactivation activity.

While direct acetylation of HIF- $\alpha$, if any, is unlikely to be involved in HDACI-mediated repression of HIF function, the direct acetylation of p300/CBP, the other determinant of the transactivation activity of HIF complexes, has been well documented. p300 and CBP are acetyltransferases serving as general cofactors for multiple transcription factors including HIF- $\alpha$ [131]. These two proteins possess multiple domains that function as docking sites for their interaction with a variety of transcription regulators [131]. Interestingly, all those important functional domains are lysine-rich and have shown to be subjective to autoacetylation by p300 or CBP [131, 132]. Importantly, exposure of cells to HDACIs causes hyperacetylation of p300 [131]. Consistent with these observations, p300 has been reported to complex with HDAC activities [133-135]. These observations suggest that HDACI-mediated repression of HIF transactivation more likely implicates the acetylation status of p300 or CBP. A recent work revealed that the transactivation activity of HIF- $\alpha$ NAD also requires an interaction with $\mathrm{p} 300$ or CBP [136]. This interaction is mediated by $\mathrm{CH} 3$ domain, which is also one of the lysine-rich regions subjective to acetylation [131]. Therefore, it is possible that the HDACI-mediated repression of HIF- $\alpha$ NAD also involves the acetylation status of p300 or CBP. Considering that both $\mathrm{CH} 1$ and $\mathrm{CH} 3$ domains of p300 or CBP are lysine-rich and subjective to acetylation [131] and p300 or CBP physically interacts with deacetylase activity [134], one intriguing hypothesis would be that the acetylation status of $\mathrm{CH} 1$ and $\mathrm{CH} 3$ may affect their binding affinity to different transcription factors [137]. If it is true, acetylation of p300 and CBP may represent an additional mechanism for these two general coactivators to dynamically coordinate the transcriptional reprogramming of multiple genes. Finally, since multiple signaling pathways regulate HIF- $\alpha$-p300 complex, it is also possible that one or more signaling pathways are relayed by HDAC activity, or some regulators of the signaling pathways are subjective to acetylation (Figure 3).

\section{Mechanisms Underlying HDACI-Mediated Degradation of HIF-1 $\alpha$}

As histone acetylation is generally associated with enhanced gene transcription, it is common to find that HDACI enhances the transcription and de novo synthesis of proteins. It is also true in most exogenous gene expression systems including transfection of cultured cells and in vivo gene therapy. The transcription of endogenous HIF- $1 \alpha$, however, is not affected by HDACIs (Chen \& Sang, unpublished data). Previous studies from our laboratories and others have shown that HDACI treatment has little effect on the de novo translation of endogenous HIF- $1 \alpha$ protein [137]. Here we focus our discussion on HDACI-mediated degradation of HIF- $1 \alpha$.

6.1. Do Inhibitors of Class I/II HDACs Directly Enhance the Acetylation of HIF-1 $\alpha$ at Lys532? Interaction between protein acetylation and ubiquitination has been discussed in two 
recent reviews $[138,139]$. In an early report from Dr. Kim's group, the shorter mouse variant isoform mARD1225, which is a mammalian orthologue of a yeast $\mathrm{N}-\alpha$-acetylase, catalyzed $\mathrm{N}-\varepsilon$-acetylation of HIF-1- $\alpha \mathrm{ODD}$ at Lys532, promotes HIF- $1 \alpha$ recognition and ubiquitination by VHL [124]. The longer human hARD1 $1_{235}$ isoform is also known to associate with HIF- $1 \alpha$ ODD in vitro and with full length HIF- $1 \alpha$ in vivo [140]. Subsequent evidence has shown that hARD1 cannot acetylate human HIF- $1 \alpha$ in vitro [140-143]. One explanation for this discrepancy is that $\mathrm{mARD}_{225}$ has a C-terminal region that significantly differs from those of other mouse or human ARD1 [144]. An alternative possibility is that hARD1 may aggregate in vitro, and aggregated hARD1 losses its catalytic activity as an $\alpha$-acetylase [145]. Silencing of hARD1 with siRNA affected cell proliferation, but showed no effect on HIF- $1 \alpha$ stability $[141,142]$. The role of hARD1 in cell proliferation was further demonstrated in mouse xenograft tumor model [146]. Therefore, while published data suggest that $\mathrm{mARD} 1_{225}$ has a role in HIF- $1 \alpha$ stability, and hARD1 is implicated in the regulation of cell proliferation, a precise role of hARD1 in HIF- $1 \alpha$ stability remains unclear.

HIF- $1 \alpha$ is easily detectable from the immunoprecipitates by using anti-acetyl-lysine antibodies [116, 124, 147, 148]. It is also possible that HIF- $1 \alpha$ interacts with one or more acetylated proteins, thus is indirectly coprecipitated by antilysine antibody in immunoprecipitation experiments. More recently, several studies showed direct detection of HIF- $1 \alpha$ in immunoblotting with anti-acetyl-lysine antibodies [149]. The involvement of Sirt1, a member of class III deacetylase, in the regulation of HIF- $2 \alpha$ has been reported [150]. These reports generally support that HIF- $1 \alpha$ may undergo direct acetylation in cells. Nevertheless, a specific role of Lys532 in HDACI-triggered HIF- $1 \alpha$ degradation remains unclear. ODD is sufficient to mediate the HDACI-triggered HIF$1 \alpha$ instability; however, mutation of the putative acetylation site (Lys532 to Arg) failed to protect ODD from HDACIinduced degradation [18]. So far there is no direct evidence to support that HDACIs of class I/II enhance HIF- $1 \alpha$ acetylation at Lys532 in cells. Mass-Spectrometry analysis of HIF- $1 \alpha$ isolated from cells may eventually resolve the acetylation status of Lys532 of HIF- $1 \alpha$ and shed light on its role in HIF- $1 \alpha$ stability.

6.2. HDACIs Induce Ubiquitination-Independent Degradation of HIF-1 $\alpha$. In the original model proposed by Dr. Kim, HIF- $1 \alpha$ acetylation at Lys532, either catalyzed by mARD1 or induced by HDACIs, promoted HIF- $1 \alpha$ recognition and eventual ubiquitination by VHL $[118,124]$. Since HDACIs enhance the interaction between HIF- $1 \alpha$ and HSP70, an alternative ubiquitination pathway mediated by HSP70associated CHIP has been proposed [151]. Ubiquitination of proteins sequentially involves three enzyme activities termed E1, E2, and E3. Mammalian cells have a single ubiquitinactivating enzyme E1, and VHL is the HIF- $\alpha$-specific E3 ligase. Accordingly, VHL-defective cells or E1-inactivated cells accumulate high levels of HIF- $\alpha$. If HDACI-triggered HIF- $1 \alpha$ degradation was mediated by the canonical ubiquitination pathway, the process would depend on functional
E1 and VHL activity. In fact, it is reported that HDACIs decreased HIF- $1 \alpha$ levels in all cells tested, including VHL $(-/-)$ C2 and RCC4 cells, indicating that HDACI-induced HIF- $1 \alpha$ degradation is through a mechanism existing in, perhaps, all tumors, including those lacking VHL. A special cell line, Ts20TGR, contains a temperature sensitive E1 [152]. Inactivating $\mathrm{E} 1$ in this cell line by culturing the cells at $39^{\circ} \mathrm{C}$ resulted in accumulation of nonubiquitinated HIF- $1 \alpha$ [18]. Apparently, HDACIs are able to trigger degradation of the accumulated nonubiquitinated HIF- $1 \alpha$. Since the HDACI-triggered degradation can be blocked by proteasome inhibitors, but not by lysosomal inhibitors, it is clear that the proteasome system is required [18]. Based on the above facts, it is clear that HDACIs induce HIF- $1 \alpha$ destruction by a ubiquitination-independent proteasome system (UIPS), whereas the precise mechanism remains to be dissected.

6.3. Is Hsp90 the Major Player in HDACI-Triggered Degradation of HIF-1 $\alpha$ ? Studies with Hsp90 inhibitors reveal a good candidate which may be responsible for HDAC-triggered degradation of HIF- $1 \alpha$. Hsp90 is known to associate with nonnative structures of many proteins and is responsible for protein folding in general [153]. Hsp90 have three functional domains, the ATP binding domain, protein binding domain, and dimerization domain. The normal function of Hsp90 depends on its ATPase activity because it is the principal binding site for drugs that target this protein [154]. Hsp90 inhibitors have also been explored as antitumor drugs [155]. A quick comparison reveals some obvious similarities between these two groups of drugs. (1) Both HDACI and HSP90 inhibitors have been reported to destabilize various mutated HSP90 client proteins in cells; (2) both groups of drugs enhance the levels of HSP70; (3) both groups of drugs decrease client proteins' interaction with HSP90 but increase its interaction with HSP70; (4) while HDACIs apparently inhibit deacetylases, since HSP90 function requires HDAC6 activity to maintain its deacetylated states [156-160], HDACIs function as HSP90 inhibitors indirectly (Figure 4).

It has been reported by independent laboratories that molecular chaperones including HSP70 and HSP90 directly interact with HIF- $1 \alpha$, suggesting that HIF- $1 \alpha$ is one of the client proteins of the HSP machinery. Similar to HDACIs, the Hsp90 inhibitor 17-AGG triggers ubiquitination independent degradation of HIF- $1 \alpha[17,18]$. We noted that most of the reported protein degradation cases triggered by either HDACI or HSP90 inhibitor were observed in cells with normal ubiquitination system. So even though the proteins subjective to the drug-induced degradation were generally associated with ubiquitination, there is no real evidence to support that ubiquitination is an absolute prerequisite for their degradation.

6.4. Potential Role of $\alpha$-Tubulin Acetylation in HDACIsMediated Degradation of HIF-1 $\alpha$. Another possible acetylated protein that may play a role in HDACI-induced distabilization of HIF- $1 \alpha$ is the $\alpha$ subunit of tubulin heterodimers ( $\alpha$-tubulin). $\alpha$-tubulin is an important component for the 


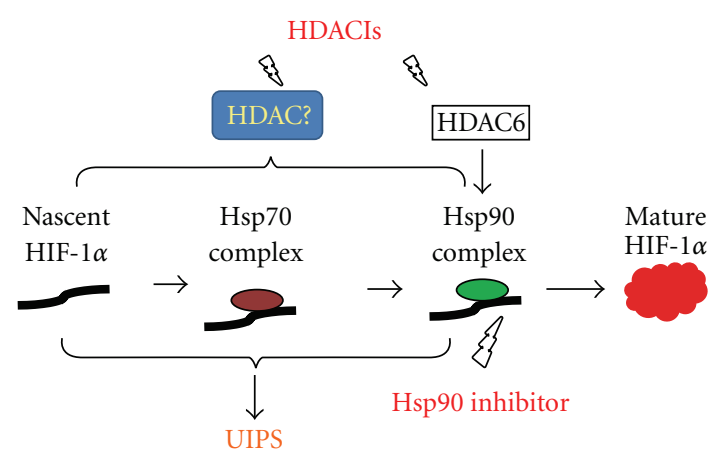

FIGURE 4: Acetylated Proteins Potentially Involved in the Control of HIF- $1 \alpha$ Maturation and Stability. HDACIs may lead to hyperacetylation of one or more proteins involved in the folding process of HIF- $1 \alpha$. Similar to HSP90 inhibition-caused blockage of normal folding and mature processes of HIF- $1 \alpha$, unfolded or misfolded HIF- $1 \alpha$ remains interacting with HSP70, which may eventually trigger a ubiquitinationindependent degradation process.

formation of microtubules and other cellular structures with a variety of functions. The acetylation of $\alpha$-tubulin was discovered long before the identification of histone deacetylase and protein acetyl transferases [161]. Its acetylation at Lys40 is a marker of stabilized microtubules $[41,43,162]$ and is regulated by HDAC6 [163]. In addition, HDAC6 provides a link between protein acetylation and ubiquitination [164], suggesting a role in regulating protein stability. Since a role of HDAC6 in HIF- $1 \alpha$ stability has been proposed $[18,41,137]$, one possibility is that microtubule dynamics may somehow be required for HIF- $1 \alpha$ stabilization. This hypothesis is supported by evidence that the small molecules disrupting the dynamics of microtubules also destabilize HIF1 $\alpha[113,114,165]$. However, how and why microtubule dynamics affects HIF- $1 \alpha$ stability remains unknown.

\section{The Acetylases and Deacetylases Involved in HIF Function}

Because of the complexity and possible functional redundancy, it may be difficult to identify an individual member that is exclusively responsible for the regulation of HIF acetylation and function. As discussed above, the role of hARD1 in HIF- $1 \alpha$ acetylation is controversial. A role of HDAC7 in regulating HIF-1 function was first proposed, based on its interaction with HIF- $1 \alpha$ but not HIF- $2 \alpha$ [117]. HDAC7 was found to increase the transactivation activity of HIF-1, and it is thought to be a transactivation coactivator of HIF-1 [117]. So far several Class II HDACs have been proposed to regulate HIF- $1 \alpha$ stability [116]. However, since HDAC7 does not interact with HIF-2 $\alpha$, it cannot be used to fully explain the repressive effects of HDACIs on HIF$2 \alpha \mathrm{CAD}$. It is shown that HDAC4 and HDAC6 coimmunoprecopitated with HIF- $1 \alpha$ and the specific inhibition of HDAC4 and HDAC6 repress HIF- $1 \alpha$ stability [116]. It is possible that multiple deacetylases are involved in HDACIinduced modulation of HIF function, and that different cell types, different physiological conditions or signaling pathways may implicate different HDACs in the regulation of HIF function.

\section{Conclusions and Perspective}

The above discussion is based on experimental evidence and published literature that may link the biochemical effects of HDACIs to the repression of HIF function. The discussions are generally focused on deacetylases, acetylation substrates, and their potential relevance to the regulation of HIF function. It is clear that the transcription complexes of HIF-1 and HIF-2 require an activity of type I/II deacetylase for their transactivation activity. This deacetylase-dependent transactivation represents a unique feature of HIF function. It is also conclusive that higher doses of HDACIs induce the degradation of HIF- $1 \alpha$ through a proteasomedependent pathway. This degradation can be mediated by an ubiquitination-independent mechanism. We expect further investigation in this field would bring new insight into the molecular and biochemical mechanisms underlying the antiHIF and antiangiogenic effects of inhibitors of type I/II HDACs. It is also important to point out that a member of the class III HDACs, Sirt1, has been reported to deacetylate HIF- $1 \alpha$ and HIF- $2 \alpha$ and repress HIF- $\alpha$ activity $[150,166]$, further showing the complexity of effect of acetylation on HIF function. A thorough understanding of the regulation of HIF- $\alpha$ by protein acetylation is essential for future exploration aiming to modulate HIF function in vivo by targeting HDACs.

While it is conclusive that in addition to serving as epigenetic therapeutics, the inhibitors for class I and II deacetylases also repress HIF function, the underlying mechanisms remain far from clear. A better understanding of the mechanisms may be beneficial not only for better efficacy of cancer therapy, but also for prevention of side effects to normal organs. Particularly, given the large number of deacetylases and their important roles in transcriptional regulation, epigenetic programming, chromosomal remodeling, and other cellular processes, it is possible that nonselectively blocking deacetylases may cause unpredictable side effects. Obviously, a nonexhaustive list of imminent future directions should include (1) identifying the acetylases and deacetylases involved in HIF function under defined conditions in specific cell types, (2) identifying the HIF regulatory 
factors subjective to acetylation, (3) defining the specific acetylation sites of their substrates and their relevance to HIF- $\alpha$, (4) defining the upstream signaling pathways that regulate HIF function through protein acetylation. At least, a recent elegant study has linked cellular metabolic to protein acetylation [167].

Finally, because it is more difficult to destroy HIF- $1 \alpha$ protein, understanding the molecular basis of HDACI-mediated repression of HIF- $\alpha$ transactivation activity is expected to elucidate novel ways to repress HIF- $\alpha$ transactivation potential, regardless of its protein levels or stability. Considering that HIF function is required for the maintenance of oxygen and nutrient supply and for prevention of cell death under hypoxic conditions, global repression of HIF- $\alpha$ activity in the entire body, particularly for long-term use, may affect chronic adaptation required for ischemic disorders. On the other hand, since HIF function and disregulated expression of VEGF play roles in tissue damage caused by ischemiareperfusion, HDACI-mediated repression of HIF may prove to be beneficial for acute ischemia [168]. The effects of HDACIs on endothelial, bone marrow, neuronal, and circulatory systems warrant a thorough interrogation [169, 170]. Taken the potential adverse effects into consideration, a lesion-specific activation of prodrugs, which can be either HDACIs or compounds specifically regulating HIF function, may become an exciting exploration.

\section{Abbreviations}

CAD: Carboxyl-terminal transactivation domain

CHIP: Carboxyl terminus of HSP70-interacting protein

FDA: $\quad$ Food and Drug Administration (USA)

FIH: Factor inhibiting HIF-1

HAT: Histone acetyltransferase

HADC: Histone deacetylase

HDACI: Histone deacetylase inhibitor

HIF: Hypoxia-inducible factors

HSP: Heat shock protein

HUPS: Hydroxylation-ubiquitination-proteasomal system

NAD: Amino-terminal transactivation domain

ODD: Oxygen-dependent degradation domain

PHD: Prolyl hydroxylases

TAP: $\quad$ Transactivation potential

UIPS: Ubiquitination independent proteasomal system

VEGF: vascular endothelial growth factor.

\section{Acknowledgments}

Research work in Dr. Sang's lab is supported in part by Grants K01-CA098809 and R01-CA129494 (to N. Sang) from NCI, National Institutes of Health (NIH), and start-up fund from Drexel University. The authors thank Ms. A. Rajan for proofreading the manuscript.

\section{References}

[1] D. L. Schwartz, J. A. Bankson, R. Lemos Jr. et al., "Radiosensitization and stromal imaging response correlates for the HIF1 inhibitor PX-478 given with or without chemotherapy in pancreatic cancer," Molecular Cancer Therapeutics, vol. 9, no. 7, pp. 2057-2067, 2010.

[2] G. L. Semenza, "Defining the role of hypoxia-inducible factor 1 in cancer biology and therapeutics," Oncogene, vol. 29, no. 5, pp. 625-634, 2010.

[3] A. Daponte, M. Ioannou, I. Mylonis et al., "Prognostic significance of hypoxia-inducible factor 1 alpha(HIF-1alpha) expression in serous ovarian cancer: an immunohistochemical study," BMC Cancer, vol. 8, article no. 335, 2008.

[4] C. Gómez-Raposo, M. Mendiola, J. Barriuso, E. Casado, D. Hardisson, and A. Redondo, "Angiogenesis and ovarian cancer," Clinical \& Translational Oncology, vol. 11, no. 9, pp. 564-571, 2009.

[5] H. Jiang and Y. Feng, "Hypoxia-inducible factor $1 \alpha$ (HIF$1 \alpha$ ) correlated with tumor growth and apoptosis in ovarian cancer," International Journal of Gynecological Cancer, vol. 16, supplement 1, pp. 405-412, 2006.

[6] J. M. Brown and W. R. Wilson, "Exploiting tumour hypoxia in cancer treatment," Nature Reviews Cancer, vol. 4, no. 6, pp. 437-447, 2004.

[7] A. Giaccia, B. G. Siim, and R. S. Johnson, "HIF-1 as a target for drug development," Nature Reviews Drug Discovery, vol. 2, no. 10, pp. 803-811, 2003.

[8] G. Powis and L. Kirkpatrick, "Hypoxia inducible factor- $1 \alpha$ as a cancer drug target," Molecular Cancer Therapeutics, vol. 3, no. 5, pp. 647-654, 2004.

[9] G. L. Semenza, "Targeting HIF-1 for cancer therapy," Nature Reviews Cancer, vol. 3, no. 10, pp. 721-732, 2003.

[10] S. J. Welsh and G. Powis, "Hypoxia inducible factor as a cancer drug target," Current Cancer Drug Targets, vol. 3, no. 6, pp. 391-405, 2003.

[11] D. Kong, E. J. Park, A. G. Stephen et al., "Echinomycin, a small-molecule inhibitor of hypoxia-inducible factor-1 DNA-binding activity," Cancer Research, vol. 65, no. 19, pp. 9047-9055, 2005.

[12] C. Tan, R. G. De Noronha, A. J. Roecker et al., "Identification of a novel small-molecule inhibitor of the hypoxia-inducible factor 1 pathway," Cancer Research, vol. 65, no. 2, pp. 605612, 2005.

[13] S. Welsh, R. Williams, L. Kirkpatrick, G. Paine-Murrieta, and G. Powis, "Antitumor activity and pharmacodynamic properties of PX-478, an inhibitor of hypoxia-inducible factor-1 $\alpha$," Molecular Cancer Therapeutics, vol. 3, no. 3, pp. 233-244, 2004.

[14] D. C. Drummond, C. O. Noble, D. B. Kirpotin, Z. Guo, G. K. Scott, and C. C. Benz, "Clinical development of histone deacetylase inhibitors as anticancer agents," Annual Review of Pharmacology and Toxicology, vol. 45, pp. 495-528, 2005.

[15] R. W. Johnstone and J. D. Licht, "Histone deacetylase inhibitors in cancer therapy: is transcription the primary target?" Cancer Cell, vol. 4, no. 1, pp. 13-18, 2003.

[16] P. A. Marks, V. M. Richon, R. Breslow, and R. A. Rifkind, "Histone deacetylase inhibitors as new cancer drugs," Current Opinion in Oncology, vol. 13, no. 6, pp. 477-483, 2001.

[17] D. M. Fath, X. Kong, D. Liang et al., "Histone deacetylase inhibitors repress the transactivation potential of hypoxiainducible factors independently of direct acetylation of HIFa," Journal of Biological Chemistry, vol. 281, no. 19, pp. 13612-13619, 2006.

[18] X. Kong, Z. Lin, D. Liang, D. Fath, N. Sang, and J. Caro, "Histone deacetylase inhibitors induce VHL and ubiquitinindependent proteasomal degradation of hypoxia-inducible factor 1 $\alpha$," Molecular and Cellular Biology, vol. 26, no. 6, pp. 2019-2028, 2006. 
[19] J. Ahringer, "NuRD and SIN3: histone deacetylase complexes in development," Trends in Genetics, vol. 16, no. 8, pp. 351$356,2000$.

[20] X.-J. Yang and S. Grégoire, "Class II histone deacetylases: from sequence to function, regulation, and clinical implication," Molecular and Cellular Biology, vol. 25, no. 8, pp. 2873 2884, 2005.

[21] X.-J. Yang and E. Seto, "Collaborative spirit of histone deacetylases in regulating chromatin structure and gene expression," Current Opinion in Genetics and Development, vol. 13, no. 2, pp. 143-153, 2003.

[22] C. Choudhary, C. Kumar, F. Gnad et al., "Lysine acetylation targets protein complexes and co-regulates major cellular functions," Science, vol. 325, no. 5942, pp. 834-840, 2009.

[23] P. Bali, M. Pranpat, J. Bradner et al., "Inhibition of histone deacetylase 6 acetylates and disrupts the chaperone function of heat shock protein 90: a novel basis for antileukemia activity of histone deacetylase inhibitors," Journal of Biological Chemistry, vol. 280, no. 29, pp. 26729-26734, 2005.

[24] P. A. Marks and M. Dokmanovic, "Histone deacetylase inhibitors: discovery and development as anticancer agents," Expert Opinion on Investigational Drugs, vol. 14, no. 12, pp. 1497-1511, 2005.

[25] G. Blander and L. Guarente, "The Sir2 family of protein deacetylases," Annual Review of Biochemistry, vol. 73, pp. 417-435, 2004.

[26] M. Goodson, B. A. Jonas, and M. A. Privalsky, "Corepressors: custom tailoring and alterations while you wait," Nuclear Receptor Signal, vol. 3, article no. e003, 2005.

[27] M. G. Rosenfeld, V. V. Lunyak, and C. K. Glass, "Sensors and signals: a coactivator/corepressor/epigenetic code for integrating signal-dependent programs of transcriptional response," Genes and Development, vol. 20, no. 11, pp. 14051428, 2006.

[28] J. Joseph, G. Mudduluru, S. Antony, S. Vashistha, P. Ajitkumar, and K. Somasundaram, "Expression profiling of sodium butyrate $(\mathrm{NaB})$-treated cells: identification of regulation of genes related to cytokine signaling and cancer metastasis by NaB," Oncogene, vol. 23, no. 37, pp. 6304-6315, 2004.

[29] A. Rascle, J. A. Johnston, and B. Amati, "Deacetylase activity is required for recruitment of the basal transcription machinery and transactivation by STAT5," Molecular and Cellular Biology, vol. 23, no. 12, pp. 4162-4173, 2003.

[30] T. Ikenoue, K. Inoki, B. Zhao, and K.-L. Guan, "PTEN acetylation modulates its interaction with PDZ domain," Cancer Research, vol. 68, no. 17, pp. 6908-6912, 2008.

[31] P.-O. Hasselgren, "Ubiquitination, phosphorylation, and acetylation-triple threat in muscle wasting," Journal of Cellular Physiology, vol. 213, no. 3, pp. 679-689, 2007.

[32] B. Chen and C. L. Cepko, "HDAC4 regulates neuronal survival in normal and diseased retinas," Science, vol. 323, no. 5911, pp. 256-259, 2009.

[33] E. A. Miska, E. Langley, D. Wolf, C. Karlsson, J. Pines, and T. Kouzarides, "Differential localization of HDAC4 orchestrates muscle differentiation," Nucleic Acids Research, vol. 29, no. 16, pp. 3439-3447, 2001.

[34] R. B. Vega, K. Matsuda, J. Oh et al., "Histone deacetylase 4 controls chondrocyte hypertrophy during skeletogenesis," Cell, vol. 119, no. 4, pp. 555-566, 2004.

[35] A. H. Wang, N. R. Bertos, M. Vezmar et al., "HDAC4, a human histone deacetylase related to yeast HDA1, is a transcriptional corepressor," Molecular and Cellular Biology, vol. 19, no. 11, pp. 7816-7827, 1999.
[36] E. Y. Huang, J. Zhang, E. A. Miska, M. G. Guenther, T. Kouzarides, and M. A. Lazar, "Nuclear receptor corepressors partner with class II histone deacetylases in a Sin3independent repression pathway," Genes and Development, vol. 14 , no. 1 , pp. 45-54, 2000.

[37] R. B. Vega, B. C. Harrison, E. Meadows et al., "Protein kinases $\mathrm{C}$ and $\mathrm{D}$ mediate agonist-dependent cardiac hypertrophy through nuclear export of histone deacetylase 5," Molecular and Cellular Biology, vol. 24, no. 19, pp. 8374-8385, 2004.

[38] C. Lemercier, A. Verdel, B. Galloo, S. Curtet, M.-P. Brocard, and S. Khochbin, "mHDA1/HDAC5 histone deacetylase interacts with and represses MEF2A transcriptional activity," Journal of Biological Chemistry, vol. 275, no. 20, pp. 1559415599, 2000.

[39] J. J. Kovacs, P. J. M. Murphy, S. Gaillard et al., "HDAC6 regulates Hsp90 acetylation and chaperone-dependent activation of glucocorticoid receptor," Molecular Cell, vol. 18, no. 5, pp. 601-607, 2005.

[40] S. J. Haggarty, K. M. Koeller, J. C. Wong, C. M. Grozinger, and S. L. Schreiber, "Domain-selective small-molecule inhibitor of histone deacetylase 6 (HDAC6)-mediated tubulin deacetylation," Proceedings of the National Academy of Sciences of the United States of America, vol. 100, no. 8, pp. 4389-4394, 2003.

[41] C. Hubbert, A. Guardiola, R. Shao et al., "HDAC6 is a microtubule-associated deacetylase," Nature, vol. 417, no. 6887, pp. 455-458, 2002.

[42] A. Matsuyama, T. Shimazu, Y. Sumida et al., "In vivo destabilization of dynamic microtubules by HDAC6-mediated deacetylation," EMBO Journal, vol. 21, no. 24, pp. 6820-6831, 2002.

[43] Y. Zhang, N. Li, C. Caron et al., "HDAC-6 interacts with and deacetylates tubulin and microtubules in vivo," EMBO Journal, vol. 22, no. 5, pp. 1168-1179, 2003.

[44] A. Rodriguez-Gonzalez, T. Lin, A. K. Ikeda, T. SimmsWaldrip, C. Fu, and K. M. Sakamoto, "Role of the aggresome pathway in cancer: targeting histone deacetylase 6-dependent protein degradation," Cancer Research, vol. 68, no. 8, pp. 2557-2560, 2008.

[45] Y. Nakamura, M. Ogura, D. Tanaka, and N. Inagaki, "Localization of mouse mitochondrial SIRT proteins: shift of SIRT3 to nucleus by co-expression with SIRT5," Biochemical and Biophysical Research Communications, vol. 366, no. 1, pp. 174-179, 2008.

[46] G.-G. Liou, J. C. Tanny, R. G. Kruger, T. Walz, and D. Moazed, "Assembly of the SIR complex and its regulation by $\mathrm{O}$-acetyl-ADP-ribose, a product of NAD-dependent histone deacetylation," Cell, vol. 121, no. 4, pp. 515-527, 2005.

[47] T. Inoue, M. Hiratsuka, M. Osaki, and M. Oshimura, "The molecular biology of mammalian SIRT proteins: SIRT2 in cell cycle regulation," Cell Cycle, vol. 6, no. 9, pp. 1011-1018, 2007.

[48] B. J. North, B. L. Marshall, M. T. Borra, J. M. Denu, and E. Verdin, "The human Sir2 ortholog, SIRT2, is an $\mathrm{NAD}^{+}$dependent tubulin deacetylase," Molecular Cell, vol. 11, no. 2, pp. 437-444, 2003.

[49] A. Vaquero, R. Sternglanz, and D. Reinberg, "NAD ${ }^{+}$ dependent deacetylation of $\mathrm{H} 4$ lysine 16 by class III HDACs," Oncogene, vol. 26, no. 37, pp. 5505-5520, 2007.

[50] S. Kume, T. Uzu, K. Horiike et al., "Calorie restriction enhances cell adaptation to hypoxia through Sirt1-dependent mitochondrial autophagy in mouse aged kidney," Journal of Clinical Investigation, vol. 120, no. 4, pp. 1043-1055, 2010.

[51] T. Araki, Y. Sasaki, and J. Milbrandt, "Increased nuclear NAD biosynthesis and SIRT1 activation prevent axonal 
degeneration," Science, vol. 305, no. 5686, pp. 1010-1013, 2004.

[52] M. Fainzilber and J. L. Twiss, "Tracking in the wlds-the hunting of the SIRT and the luring of the draper," Neuron, vol. 50, no. 6, pp. 819-821, 2006.

[53] A. Villagra, F. Cheng, H-W. Wang et al., "The histone deacetylase HDAC11 regulates the expression of interleukin 10 and immune tolerance," Nature Immunology, vol. 10, pp. 92-100, 2008.

[54] X.-J. Yang and E. Seto, "HATs and HDACs: from structure, function and regulation to novel strategies for therapy and prevention," Oncogene, vol. 26, no. 37, pp. 5310-5318, 2007.

[55] Y.-Y. Lin, J.-Y. Lu, J. Zhang et al., "Protein acetylation microarray reveals that NuA4 controls key metabolic target regulating gluconeogenesis," Cell, vol. 136, no. 6, pp. 10731084, 2009.

[56] S. C. Kim, R. Sprung, Y. Chen et al., "Substrate and functional diversity of lysine acetylation revealed by a proteomics survey," Molecular Cell, vol. 23, no. 4, pp. 607-618, 2006.

[57] I. V. Gregoretti, Y.-M. Lee, and H. V. Goodson, "Molecular evolution of the histone deacetylase family: functional implications of phylogenetic analysis," Journal of Molecular Biology, vol. 338, no. 1, pp. 17-31, 2004.

[58] A. J. M. De Ruijter, A. H. Van Gennip, H. N. Caron, S. Kemp, and A. B. P. Van Kuilenburg, "Histone deacetylases (HDACs): characterization of the classical HDAC family," Biochemical Journal, vol. 370, no. 3, pp. 737-749, 2003.

[59] A. R. Guardiola and T.-P. Yao, "Molecular cloning and characterization of a novel histone deacetylase HDAC10," Journal of Biological Chemistry, vol. 277, no. 5, pp. 33503356, 2002.

[60] H.-Y. Kao, C.-H. Lee, A. Komarov, C. C. Han, and R. M. Evans, "Isolation and characterization of mammalian HDAC10, a novel histone deacetylase," Journal of Biological Chemistry, vol. 277, no. 1, pp. 187-193, 2002.

[61] L. Gao, M. A. Cueto, F. Asselbergs, and P. Atadja, "Cloning and functional characterization of HDAC11, a novel member of the human histone deacetylase family," Journal of Biological Chemistry, vol. 277, no. 28, pp. 25748-25755, 2002.

[62] J. E. Bolden, M. J. Peart, and R. W. Johnstone, "Anticancer activities of histone deacetylase inhibitors," Nature Reviews Drug Discovery, vol. 5, no. 9, pp. 769-784, 2006.

[63] P. A. Marks and R. Breslow, "Dimethyl sulfoxide to vorinostat: development of this histone deacetylase inhibitor as an anticancer drug," Nature Biotechnology, vol. 25, no. 1, pp. 84 90, 2007.

[64] T. J. Greshock, D. M. Johns, Y. Noguchi, and R. M. Williams, "Improved total synthesis of the potent HDAC inhibitor FK228 (FR-901228)," Organic Letters, vol. 10, no. 4, pp. 613$616,2008$.

[65] A. F. Taghiyev, N. V. Guseva, M. T. Sturm, O. W. Rokhlin, and M. B. Cohen, "Trichostatin a (TSA) sensitizes the human prostatic cancer cell line DU145 to death receptor ligands treatment," Cancer Biology and Therapy, vol. 4, no. 4, pp. 382-390, 2005.

[66] D. M. Vigushin, S. Ali, P. E. Pace et al., "Trichostatin A is a histone deacetylase inhibitor with potent antitumor activity against breast cancer in vivo," Clinical Cancer Research, vol. 7, no. 4, pp. 971-976, 2001.

[67] D. M. Lucas, L. Alinari, D. A. West et al., "The novel deacetylase inhibitor AR-42 demonstrates pre-clinical activity in Bcell malignancies in vitro and in vivo," PLoS One, vol. 5, no. 6, article no. e10941, 2010.
[68] C.-J. Lai, R. Bao, X. Tao et al., "CUDC-101, a multitargeted inhibitor of histone deacetylase, epidermal growth factor receptor, and human epidermal growth factor receptor 2, exerts potent anticancer activity," Cancer Research, vol. 70, no. 9, pp. 3647-3656, 2010.

[69] G. L. Semenza, "Regulation of mammalian O2 homeostasis by hypoxia-inducible factor 1," Annual Review of Cell and Developmental Biology, vol. 15, pp. 551-578, 1999.

[70] G. L. Semenza, "Expression of hypoxia-inducible factor 1: mechanisms and consequences," Biochemical Pharmacology, vol. 59, no. 1, pp. 47-53, 2000.

[71] C.-J. Hu, A. Sataur, L. Wang, H. Chen, and M. C. Simon, "The N-terminal transactivation domain confers target gene specificity of hypoxia-inducible factors HIF- $1 \alpha$ and HIF- $2 \alpha$," Molecular Biology of the Cell, vol. 18, no. 11, pp. 4528-4542, 2007.

[72] C.-J. Hu, L.-Y. Wang, L. A. Chodosh, B. Keith, and M. C. Simon, "Differential roles of hypoxia-inducible factor $1 \alpha$ (HIF- $1 \alpha$ ) and HIF- $2 \alpha$ in hypoxic gene regulation," Molecular and Cellular Biology, vol. 23, no. 24, pp. 9361-9374, 2003.

[73] V. A. Carroll and M. Ashcroft, "Role of hypoxia-inducible factor (HIF)- $1 \alpha$ versus HIF- $2 \alpha$ in the regulation of HIF target genes in response to hypoxia, insulin-like growth factorI, or loss of von Hippel-Lindau function: implications for targeting the HIF pathway," Cancer Research, vol. 66, no. 12, pp. 6264-6270, 2006.

[74] W. G. Kaelin Jr., "The von Hippel-Lindau tumor suppressor protein and clear cell renal carcinoma," Clinical Cancer Research, vol. 13, no. 2, pp. 680s-684s, 2007.

[75] D. Liao and R. S. Johnson, "Hypoxia: a key regulator of angiogenesis in cancer," Cancer and Metastasis Reviews, vol. 26, no. 2, pp. 281-290, 2007.

[76] R. Bos, P. J. Van Diest, J. S. De Jong, P. Van Der Groep, P. Van Der Valk, and E. Van Der Wall, "Hypoxia-inducible factor- $1 \alpha$ is associated with angiogenesis, and expression of bFGF, PDGF-BB, and EGFR in invasive breast cancer," Histopathology, vol. 46, no. 1, pp. 31-36, 2005.

[77] M. Calvani, A. Rapisarda, B. Uranchimeg, R. H. Shoemaker, and G. Melillo, "Hypoxic induction of an HIF- $1 \alpha$-dependent bFGF autocrine loop drives angiogenesis in human endothelial cells," Blood, vol. 107, no. 7, pp. 2705-2712, 2006.

[78] W. G. Kaelin Jr., "The von Hippel-Lindau protein, HIF hydroxylation, and oxygen sensing," Biochemical and Biophysical Research Communications, vol. 338, no. 1, pp. 627628, 2005.

[79] D. Lando, J. J. Gorman, M. L. Whitelaw, and D. J. Peet, "Oxygen-dependent regulation of hypoxia-inducible factors by prolyl and asparaginyl hydroxylation," European Journal of Biochemistry, vol. 270, no. 5, pp. 781-790, 2003.

[80] G. L. Semenza, "Hydroxylation of HIF-1: oxygen sensing at the molecular level," Physiology, vol. 19, no. 4, pp. 176-182, 2004.

[81] L. E. Huang, J. Gu, M. Schau, and H. F. Bunn, "Regulation of hypoxia-inducible factor $1 \alpha$ is mediated by an O2-dependent degradation domain via the ubiquitin-proteasome pathway," Proceedings of the National Academy of Sciences of the United States of America, vol. 95, no. 14, pp. 7987-7992, 1998.

[82] S. Salceda and J. Caro, "Hypoxia-inducible factor $1 \alpha$ (HIF$1 \alpha$ ) protein is rapidly degraded by the ubiquitin-proteasome system under normoxic conditions. Its stabilization by hypoxia depends on redox-induced changes," Journal of Biological Chemistry, vol. 272, no. 36, pp. 22642-22647, 1997.

[83] Z. Arany, L. E. Huang, R. Eckner et al., "An essential role for p300/CBP in the cellular response to hypoxia," Proceedings 
of the National Academy of Sciences of the United States of America, vol. 93, no. 23, pp. 12969-12973, 1996.

[84] P. Carrero, K. Okamoto, P. Coumailleau, S. A. O’Brien, H. Tanaka, and L. Poellinger, "Redox-regulated recruitment of the transcriptional coactivators CREB-binding protein and SRC-1 to hypoxia, inducible factor $1 \alpha$, Molecular and Cellular Biology, vol. 20, no. 1, pp. 402-415, 2000.

[85] D. Lando, D. J. Peet, D. A. Whelan, J. J. Gorman, and M. L. Whitelaw, "Asparagine hydroxylation of the HIF transactivation domain: a hypoxic switch," Science, vol. 295, no. 5556, pp. 858-861, 2002.

[86] N. Sang, J. Fang, V. Srinivas, I. Leshchinsky, and J. Caro, "Carboxyl-terminal transactivation activity of hypoxiainducible factor $1 \alpha$ is governed by a von Hippel-Lindau protein-independent, hydroxylation-regulated association with p300/CBP," Molecular and Cellular Biology, vol. 22, no. 9, pp. 2984-2992, 2002.

[87] R. Paddenberg, A. Goldenberg, P. Faulhammer, R. C. BraunDullaeus, and W. Kummer, "Mitochondrial complex II is essential for hypoxia-induced ROS generation and vasoconstriction in the pulmonary vasculature," Advances in Experimental Medicine and Biology, vol. 536, pp. 163-169, 2002.

[88] R. D. Guzy, B. Hoyos, E. Robin et al., "Mitochondrial complex III is required for hypoxia-induced ROS production and cellular oxygen sensing," Cell Metabolism, vol. 1, no. 6, pp. 401-408, 2005.

[89] M. Meng, S. Chen, T. Lao, D. Liang, and N. Sang, "Nitrogen anabolism underlies the importance of glutaminolysis in proliferating cells," Cell Cycle, vol. 9, no. 19, pp. 3921-3932, 2010.

[90] G. L. Semenza, "Intratumoral hypoxia, radiation resistance, and HIF-1," Cancer Cell, vol. 5, no. 5, pp. 405-406, 2004.

[91] G. L. Semenza, "Development of novel therapeutic strategies that target HIF-1," Expert Opinion on Therapeutic Targets, vol. 10, no. 2, pp. 267-280, 2006.

[92] H. Zhong, K. Chiles, D. Feldser et al., "Modulation of hypoxia-inducible factor $1 \alpha$ expression by the epidermal growth factor/phosphatidylinositol 3kinase/PTEN/AKT/FRAP pathway in human prostate cancer cells: implications for tumor angiogenesis and therapeutics," Cancer Research, vol. 60, no. 6, pp. 1541-1545, 2000.

[93] P. Vaupel, M. Höckel, and A. Mayer, "Detection and characterization of tumor hypoxia using $\mathrm{pO}_{2}$ histography," Antioxidants and Redox Signaling, vol. 9, no. 8, pp. 12211235, 2007.

[94] H. E. Ryan, J. Lo, and R. S. Johnson, "HIF- $1 \alpha$ is required for solid tumor formation and embryonic vascularization," EMBO Journal, vol. 17, no. 11, pp. 3005-3015, 1998.

[95] H. E. Ryan, M. Poloni, W. McNulty et al., "Hypoxia-inducible factor- $1 \alpha$ is a positive factor in solid tumor growth," Cancer Research, vol. 60, no. 15, pp. 4010-4015, 2000.

[96] K. Hirota and G. L. Semenza, "Regulation of angiogenesis by hypoxia-inducible factor 1," Critical Reviews in Oncology/Hematology, vol. 59, no. 1, pp. 15-26, 2006.

[97] C. Bouzin and O. Feron, "Targeting tumor stroma and exploiting mature tumor vasculature to improve anti-cancer drug delivery," Drug Resistance Updates, vol. 10, no. 3, pp. 109-120, 2007.

[98] A. H. Licht, F. Müller-Holtkamp, I. Flamme, and G. Breier, "Inhibition of hypoxia-inducible factor activity in endothelial cells disrupts embryonic cardiovascular development," Blood, vol. 107, no. 2, pp. 584-590, 2006.
[99] T. Löfstedt, E. Fredlund, L. Holmquist-Mengelbier et al., "Hypoxia inducible factor- $2 \alpha$ in cancer," Cell Cycle, vol. 6, no. 8, pp. 919-926, 2007.

[100] W. G. An, M. Kanekal, M. C. Simon, E. Maltepe, M. V. Blagosklonny, and L. M. Neckers, "Stabilization of wild-type p53 by hypoxia-inducible factor 1alpha," Nature, vol. 392, no. 6674, pp. 405-408, 1998.

[101] M. V. Blagosklonny, W. G. An, L. Y. Romanova, J. Trepel, T. Fojo, and L. Neckers, "p53 inhibits hypoxia-inducible factorstimulated transcription," Journal of Biological Chemistry, vol. 273, no. 20, pp. 11995-11998, 1998.

[102] J. S. Isaacs, Y. J. Jung, D. R. Mole et al., "HIF overexpression correlates with biallelic loss of fumarate hydratase in renal cancer: novel role of fumarate in regulation of HIF stability," Cancer Cell, vol. 8, no. 2, pp. 143-153, 2005.

[103] R. Ravi, B. Mookerjee, Z. M. Bhujwalla et al., "Regulation of tumor angiogenesis by p53-induced degradation of hypoxiainducible factor $1 \alpha$," Genes and Development, vol. 14, no. 1, pp. 34-44, 2000.

[104] N. Sang, D. P. Stiehl, J. Bohensky, I. Leshchinsky, V. Srinivas, and J. Caro, "MAPK signaling up-regulates the activity of hypoxia-inducible factors by its effects on p300," Journal of Biological Chemistry, vol. 278, no. 16, pp. 14013-14019, 2003.

[105] M. A. Selak, S. M. Armour, E. D. MacKenzie et al., "Succinate links TCA cycle dysfunction to oncogenesis by inhibiting HIF- $\alpha$ prolyl hydroxylase," Cancer Cell, vol. 7, no. 1, pp. 7785, 2005.

[106] W. Zundel, C. Schindler, D. Haas-Kogan et al., "Loss of PTEN facilitates HIF-1-mediated gene expression," Genes and Development, vol. 14, no. 4, pp. 391-396, 2000.

[107] L. Neckers and K. Neckers, "Heat-shock protein 90 inhibitors as novel cancer chemotherapeutics-an update," Expert Opinion on Emerging Drugs, vol. 10, no. 1, pp. 137-149, 2005.

[108] Y. Miyata, "Hsp90 inhibitor geldanamycin and its derivatives as novel cancer chemotherapeutic agents," Current Pharmaceutical Design, vol. 11, no. 9, pp. 1131-1138, 2005.

[109] M. Bazzaro, M. K. Lee, A. Zoso et al., "Ubiquitin-proteasome system stress sensitizes ovarian cancer to proteasome inhibitor-induced apoptosis," Cancer Research, vol. 66, no. 7, pp. 3754-3763, 2006.

[110] Y. Ishii, S. Waxman, and D. Germain, "Targeting the ubiquitin-proteasome pathway in cancer therapy," AntiCancer Agents in Medicinal Chemistry, vol. 7, no. 3, pp. 359365, 2007.

[111] C. A. P. Joazeiro, K. C. Anderson, and T. Hunter, "Proteasome inhibitor drugs on the rise," Cancer Research, vol. 66, no. 16, pp. 7840-7842, 2006.

[112] J. B. Sunwoo, Z. Chen, G. Dong et al., "Novel proteasome inhibitor PS-341 inhibits activation of nuclear factor- $\kappa \mathrm{B}$, cell survival, tumor growth, and angiogenesis in squamous cell carcinoma," Clinical Cancer Research, vol. 7, no. 5, pp. 14191428,2001

[113] D. Escuin, E. R. Kline, and P. Giannakakou, "Both microtubule-stabilizing and microtubule-destabilizing drugs inhibit hypoxia-inducible factor- $1 \alpha$ accumulation and activity by disrupting microtubule function," Cancer Research, vol. 65, no. 19, pp. 9021-9028, 2005.

[114] N. J. Mabjeesh, D. Escuin, T. M. LaVallee et al., “2ME2 inhibits tumor growth and angiogenesis by disrupting microtubules and dysregulating HIF," Cancer Cell, vol. 3, no. 4, pp. 363-375, 2003.

[115] E. W. Newcomb, Y. Lukyanov, T. Schnee, M. A. Ali, L. Lan, and D. Zagzag, "Noscapine inhibits hypoxia-mediated HIFlalpha expression andangiogenesis in vitro: a novel function 
for an old drug," International Journal of Oncology, vol. 28, no. 5, pp. 1121-1130, 2006.

[116] D. Z. Qian, S. K. Kachhap, S. J. Collis et al., "Class II histone deacetylases are associated with VHL-independent regulation of hypoxia-inducible factor $1 \alpha$, Cancer Research, vol. 66 , no. 17 , pp. 8814-8821, 2006.

[117] H. Kato, S. Tamamizu-Kato, and F. Shibasaki, "Histone deacetylase 7 associates with hypoxia-inducible factor $1 \alpha$ and increases transcriptional activity," Journal of Biological Chemistry, vol. 279, no. 40, pp. 41966-41974, 2004.

[118] M. S. Kim, H. J. Kwon, Y. M. Lee et al., "Histone deacetylases induce angiogenesis by negative regulation of tumor suppressor genes," Nature Medicine, vol. 7, no. 4, pp. 437-443, 2001.

[119] E. Maltepe, G. W. Krampitz, K. M. Okazaki et al., "Hypoxia-inducible factor-dependent histone deacetylase activity determines stem cell fate in the placenta," Development, vol. 132, no. 15, pp. 3393-3403, 2005.

[120] Y. M. Lee, S.-H. Kim, H.-S. Kim et al., "Inhibition of hypoxiainduced angiogenesis by FK228, a specific histone deacetylase inhibitor, via suppression of HIF- $1 \alpha$ activity," Biochemical and Biophysical Research Communications, vol. 300, no. 1, pp. 241-246, 2003.

[121] Y. Sasakawa, Y. Naoe, T. Noto et al., "Antitumor efficacy of FK228, a novel histone deacetylase inhibitor, depends on the effect on expression of angiogenesis factors," Biochemical Pharmacology, vol. 66, no. 6, pp. 897-906, 2003.

[122] D. Zgouras, A. Wächtershäuser, D. Frings, and J. Stein, "Butyrate impairs intestinal tumor cell-induced angiogenesis by inhibiting HIF- $1 \alpha$ nuclear translocation," Biochemical and Biophysical Research Communications, vol. 300, no. 4, pp. 832-838, 2003.

[123] T. Inoue, M. Hiratsuka, M. Osaki, and M. Oshimura, "The molecular biology of mammalian SIRT proteins: SIRT2 in cell cycle regulation," Cell Cycle, vol. 6, no. 9, pp. 1011-1018, 2007.

[124] J.-W. Jeong, M.-K. Bae, M.-Y. Ahn et al., "Regulation and destabilization of HIF- $1 \alpha$ by ARD1-mediated acetylation," Cell, vol. 111, no. 5, pp. 709-720, 2002.

[125] Y. Li, Z. Yuan, B. Liu et al., "Prevention of hypoxia-induced neuronal apoptosis through histone deacetylase inhibition," Journal of Trauma, vol. 64, no. 4, pp. 863-870, 2008.

[126] H. Manabe, Y. Nasu, T. Komiyama et al., "Inhibition of histone deacetylase down-regulates the expression of hypoxiainduced vascular endothelial growth factor by rheumatoid synovial fibroblasts," Inflammation Research, vol. 57, no. 1, pp. 4-10, 2008.

[127] S. H. Kim, K. W. Kim, and J. W. Jeong, "Inhibition of hypoxia-induced angiogenesis by sodium butyrate, a histone deacetylase inhibitor, through hypoxia-inducible factor1alpha suppression," Oncology Report, vol. 17, no. 4, pp. 793797, 2007.

[128] Z. N. Demidenko, A. M. Rapisarda, M. Garayoa, P. Giannakakou, G. Melillo, and M. V. Blagosklonny, "Accumulation of hypoxia-inducible factor- $1 \alpha$ is limited by transcriptiondependent depletion," Oncogene, vol. 24, no. 30, pp. 48294838, 2005.

[129] L. H. Kasper, F. Boussouar, K. Boyd et al., "Two transactivation mechanisms cooperate for the bulk of HIF-1-responsive gene expression," EMBO Journal, vol. 24, no. 22, pp. 38463858, 2005.

[130] L. H. Kasper and P. K. Brindle, "Mammalian gene expression program resiliency: the roles of multiple coactivator mechanisms in hypoxia-responsive transcription," Cell Cycle, vol. 5, no. 2, pp. 142-146, 2006.
[131] D. P. Stiehl, D. M. Fath, D. Liang, Y. Jiang, and N. Sang, "Histone deacetylase inhibitors synergize p300 autoacetylation that regulates its transactivation activity and complex formation," Cancer Research, vol. 67, no. 5, pp. 2256-2264, 2007.

[132] M. L. Hansson, A. E. Popko-Ścibor, M. Saint Just Ribeiro et al., "The transcriptional coactivator MAML1 regulates p300 autoacetylation and HAT activity," Nucleic Acids Research, vol. 37, no. 9, pp. 2996-3006, 2009.

[133] J. C. Black, A. Mosley, T. Kitada, M. Washburn, and M. Carey, "The SIRT2 deacetylase regulates autoacetylation of p300," Molecular Cell, vol. 32, no. 3, pp. 449-455, 2008.

[134] C. Simone, P. Stiegler, S.-V. Forcales et al., "Deacetylase recruitment by the $\mathrm{C} / \mathrm{H} 3$ domain of the acetyltransferase p300," Oncogene, vol. 23, no. 12, pp. 2177-2187, 2004.

[135] H. Xiao, T. Hasegawa, and K.-I. Isobe, "p300 Collaborates with $\mathrm{Sp} 1$ and Sp3 in p21(wafl/cip1) promoter activation induced by histone deacetylase inhibitor," Journal of Biological Chemistry, vol. 275, no. 2, pp. 1371-1376, 2000.

[136] J. L. Ruas, U. Berchner-Pfannschmidt, S. Malik et al., "Complex regulation of the transactivation function of hypoxia-inducible factor- $1 \alpha$ by direct interaction with two distinct domains of the creb-binding protein/p300," Journal of Biological Chemistry, vol. 285, no. 4, pp. 2601-2609, 2010.

[137] D. Liang, X. Kong, and N. Sang, "Effects of histone deacetylase inhibitors on HIF-1," Cell Cycle, vol. 5, no. 21, pp. 24302435, 2006.

[138] K. Sadoul, C. Boyault, M. Pabion, and S. Khochbin, "Regulation of protein turnover by acetyltransferases and deacetylases," Biochimie, vol. 90, no. 2, pp. 306-312, 2008.

[139] C. Caron, C. Boyault, and S. Khochbin, "Regulatory crosstalk between lysine acetylation and ubiquitination: role in the control of protein stability," BioEssays, vol. 27, no. 4, pp. 408$415,2005$.

[140] T. Arnesen, X. Kong, R. Evjenth et al., "Interaction between HIF- $1 \alpha$ (ODD) and hARD1 does not induce acetylation and destabilization of HIF-1 $\alpha$," FEBS Letters, vol. 579, no. 28, pp. 6428-6432, 2005.

[141] R. Bilton, N. Mazure, E. Trottier et al., "Arrest-defective1 protein, an acetyltransferase, does not alter stability of hypoxia-inducible factor (HIF)- $1 \alpha$ and is not induced by hypoxia or HIF," Journal of Biological Chemistry, vol. 280, no. 35, pp. 31132-31140, 2005.

[142] T. S. Fisher, S. Des Etages, L. Hayes, K. Crimin, and B. $\mathrm{Li}$, "Analysis of ARD1 function in hypoxia response using retroviral RNA interference," Journal of Biological Chemistry, vol. 280, no. 18, pp. 17749-17757, 2005.

[143] T. A. Murray-Rust, N. J. Oldham, K. S. Hewitson, and C. J. Schofield, "Purified recombinant hARD1 does not catalyse acetylation of Lys 532 of HIF- $1 \alpha$ fragments in vitro," FEBS Letters, vol. 580, no. 8, pp. 1911-1918, 2006.

[144] S.-H. Kim, J. A. Park, J. H. Kim et al., "Characterization of ARD1 variants in mammalian cells," Biochemical and Biophysical Research Communications, vol. 340, no. 2, pp. 422-427, 2006.

[145] N. Sanchez-Puig and A. R. Fersht, "Characterization of the native and fibrillar conformation of the human nalphaacetyltransferase ard1," Protein Science, vol. 15, no. 8, pp. 1968-1976, 2006.

[146] J. H. Seo, J.-H. Cha, J.-H. Park et al., "Arrest defective 1 autoacetylation is a critical step in its ability to stimulate cancer cell proliferation," Cancer Research, vol. 70, no. 11, pp. 4422-4432, 2010. 
[147] C.-C. Chang, M.-T. Lin, B.-R. Lin et al., "Effect of connective tissue growth factor on hypoxia-inducible factor $1 \alpha$ degradation and tumor angiogenesis," Journal of the National Cancer Institute, vol. 98, no. 14, pp. 984-995, 2006.

[148] S. Lin, S.-C. Tsai, C.-C. Lee, B.-W. Wang, J.-Y. Liou, and K.G. Shyu, "Berberine inhibits HIF- $1 \alpha$ expression via enhanced proteolysis," Molecular Pharmacology, vol. 66, no. 3, pp. 612619, 2004.

[149] G. Xenaki, T. Ontikatze, R. Rajendran et al., "PCAF is an HIF- $1 \alpha$ cofactor that regulates 533 transcriptional activity in hypoxia," Oncogene, vol. 27, no. 44, pp. 5785-5796, 2008.

[150] E. M. Dioum, R. Chen, M. S. Alexander et al., "Regulation of hypoxia-inducible factor 2alpha signaling by the stressresponsive deacetylase sirtuin 1," Science, vol. 324, no. 5932, pp. 1289-1293, 2009.

[151] W. Luo, J. Zhong, R. Chang, H. Hu, A. Pandey, and G. L. Semenza, "Hsp70 and CHIP selectively mediate ubiquitination and degradation of hypoxia-inducible factor (HIF)- $1 \alpha$ but not HIF-2 $\alpha$," Journal of Biological Chemistry, vol. 285, no. 6, pp. 3651-3663, 2010.

[152] G.-C. Zeng, H. L. Ozer, and R. Hand, "Further characterization of the phenotype of ts20, a DNA(ts) mutant of BALB/3T3 cells," Experimental Cell Research, vol. 160, no. 1, pp. 184-196, 1985.

[153] J. Buchner, "Hsp90 and Co.—a holding for folding," Trends in Biochemical Sciences, vol. 24, no. 4, pp. 136-141, 1999.

[154] G. Chiosis, E. C. Lopes, and D. Solit, "Heat shock protein-90 inhibitors: a chronicle from geldanamycin to today's agents," Current Opinion in Investigational Drugs, vol. 7, no. 6, pp. 534-541, 2006.

[155] M. P. Goetz, D. O. Toft, M. M. Ames, and C. Erlichman, "The Hsp90 chaperone complex as a novel target for cancer therapy," Annals of Oncology, vol. 14, no. 8, pp. 1169-1176, 2003.

[156] J. Ai, Y. Wang, J. A. Dar et al., "HDAC6 regulates androgen receptor hypersensitivity and nuclear localization via modulating Hsp90 acetylation in castration-resistant prostate cancer," Molecular Endocrinology, vol. 23, no. 12, pp. 19631972, 2009.

[157] V. D. Kekatpure, A. J. Dannenberg, and K. Subbaramaiah, "HDAC6 modulates Hsp90 chaperone activity and regulates activation of aryl hydrocarbon receptor signaling," Journal of Biological Chemistry, vol. 284, no. 12, pp. 7436-7445, 2009.

[158] S. Basak, D. Pookot, E. J. Noonan, and R. Dahiya, "Genistein down-regulates androgen receptor by modulating HDAC6Hsp90 chaperone function," Molecular Cancer Therapeutics, vol. 7, no. 10, pp. 3195-3202, 2008.

[159] R. Rao, W. Fiskus, Y. Yang et al., "HDAC6 inhibition enhances 17-AAG mediated abrogation of hsp90 chaperone function in human leukemia cells," Blood, vol. 112, no. 5, pp. 18861893, 2008.

[160] J. J. Kovacs, P. J. M. Murphy, S. Gaillard et al., "HDAC6 regulates Hsp90 acetylation and chaperone-dependent activation of glucocorticoid receptor," Molecular Cell, vol. 18, no. 5, pp. 601-607, 2005.

[161] S. W. L'Hernault and J. L. Rosenbaum, "Chlamydomonas alpha-tubulin is posttranslationally modified by acetylation on the epsilon-amino group of a lysine," Biochemistry, vol. 24, no. 2, pp. 473-478, 1985.

[162] H. Maruta, K. Greer, and J. L. Rosenbaum, "The acetylation of alpha-tubulin and its relationship to the assembly and disassembly of microtubules," Journal of Cell Biology, vol. 103, no. 2, pp. 571-579, 1986.
[163] A. D.-A. Tran, T. P. Marmo, A. A. Salam et al., "HDAC6 deacetylation of tubulin modulates dynamics of cellular adhesions," Journal of Cell Science, vol. 120, no. 8, pp. 14691479, 2007.

[164] C. Boyault, K. Sadoul, M. Pabion, and S. Khochbin, "HDAC6, at the crossroads between cytoskeleton and cell signaling by acetylation and ubiquitination," Oncogene, vol. 26, no. 37, pp. 5468-5476, 2007.

[165] S. L. Thomas, D. Zhong, W. Zhou et al., "EF24, a novel curcumin analog, disrupts the microtubule cytoskeleton and inhibits HIF-1," Cell Cycle, vol. 7, no. 15, pp. 2409-2417, 2008.

[166] J. H. Lim, Y. M. Lee, Y. S. Chun, J. Chen, J. E. Kim, and J. W. Park, "Sirtuin 1 modulates cellular responses to hypoxia by deacetylating hypoxia-inducible factor 1alpha," Molecular cell, vol. 38, no. 6, pp. 864-878, 2010.

[167] S. Zhao, W. Xu, W. Jiang et al., "Regulation of cellular metabolism by protein lysine acetylation," Science, vol. 327, no. 5968, pp. 1000-1004, 2010.

[168] A. Granger, I. Abdullah, F. Huebner et al., "Histone deacetylase inhibition reduces myocardial ischemia-reperfusion injury in mice," FASEB Journal, vol. 22, no. 10, pp. 35493560, 2008.

[169] C. Colussi, B. Illi, J. Rosati et al., "Histone deacetylase inhibitors: keeping momentum for neuromuscular and cardiovascular diseases treatment," Pharmacological Research, vol. 62, no. 1, pp. 3-10, 2010.

[170] C. Colussi, R. Berni, J. Rosati et al., "The histone deacetylase inhibitor suberoylanilide hydroxamic acid reduces cardiac arrhythmias in dystrophic mice," Cardiovascular Research, vol. 87 , no. 1 , pp. 73-82, 2010. 

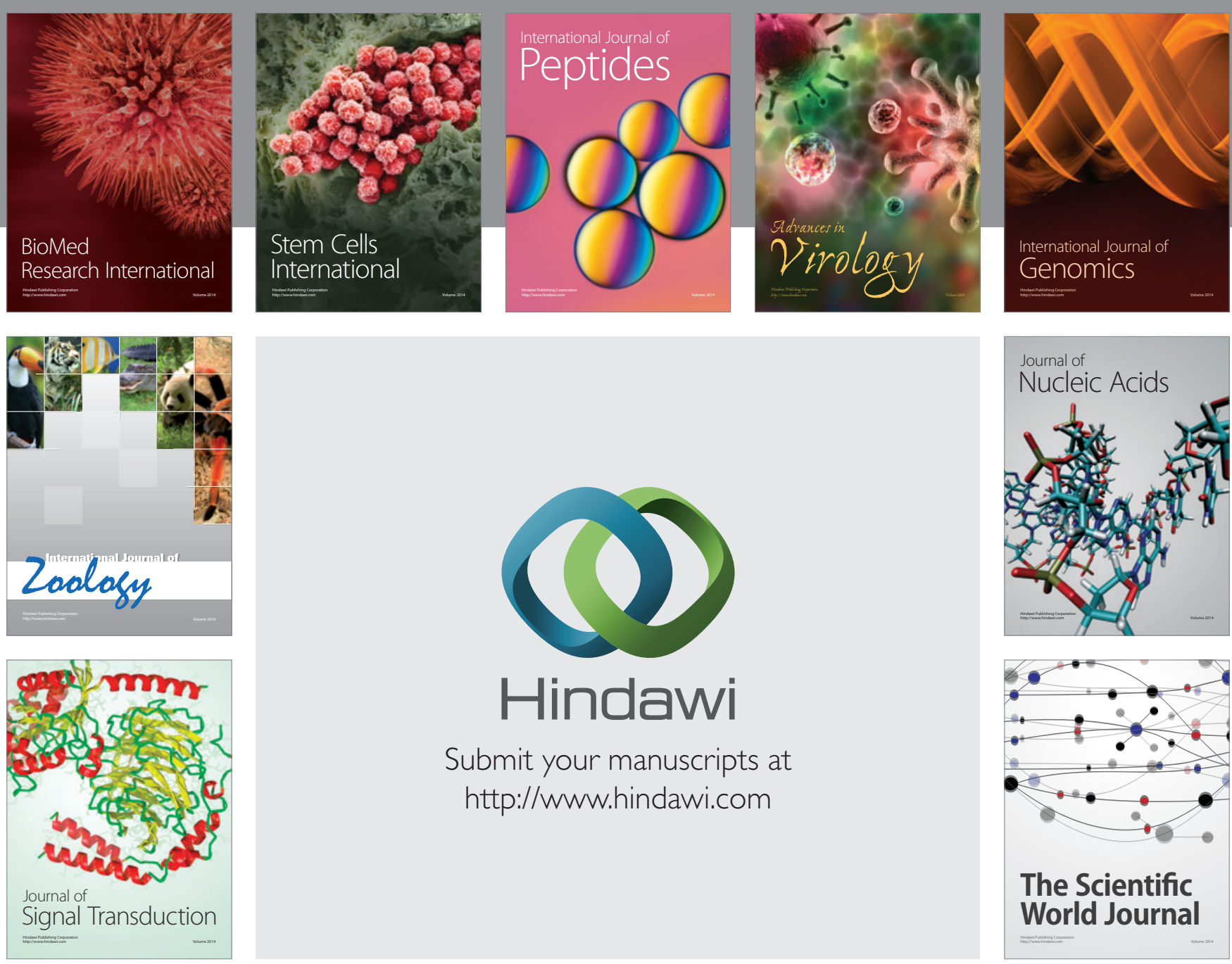

Submit your manuscripts at

http://www.hindawi.com
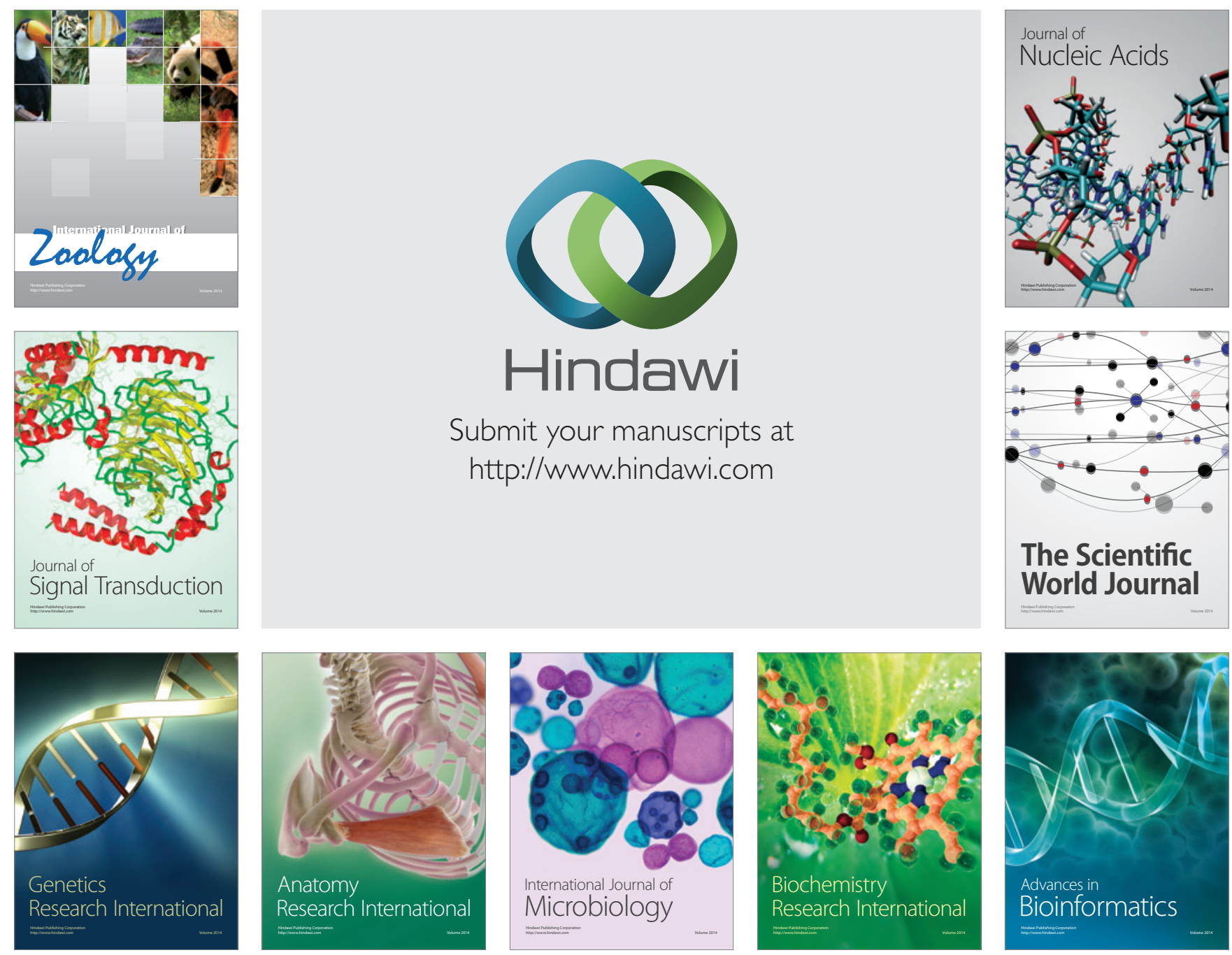

The Scientific World Journal
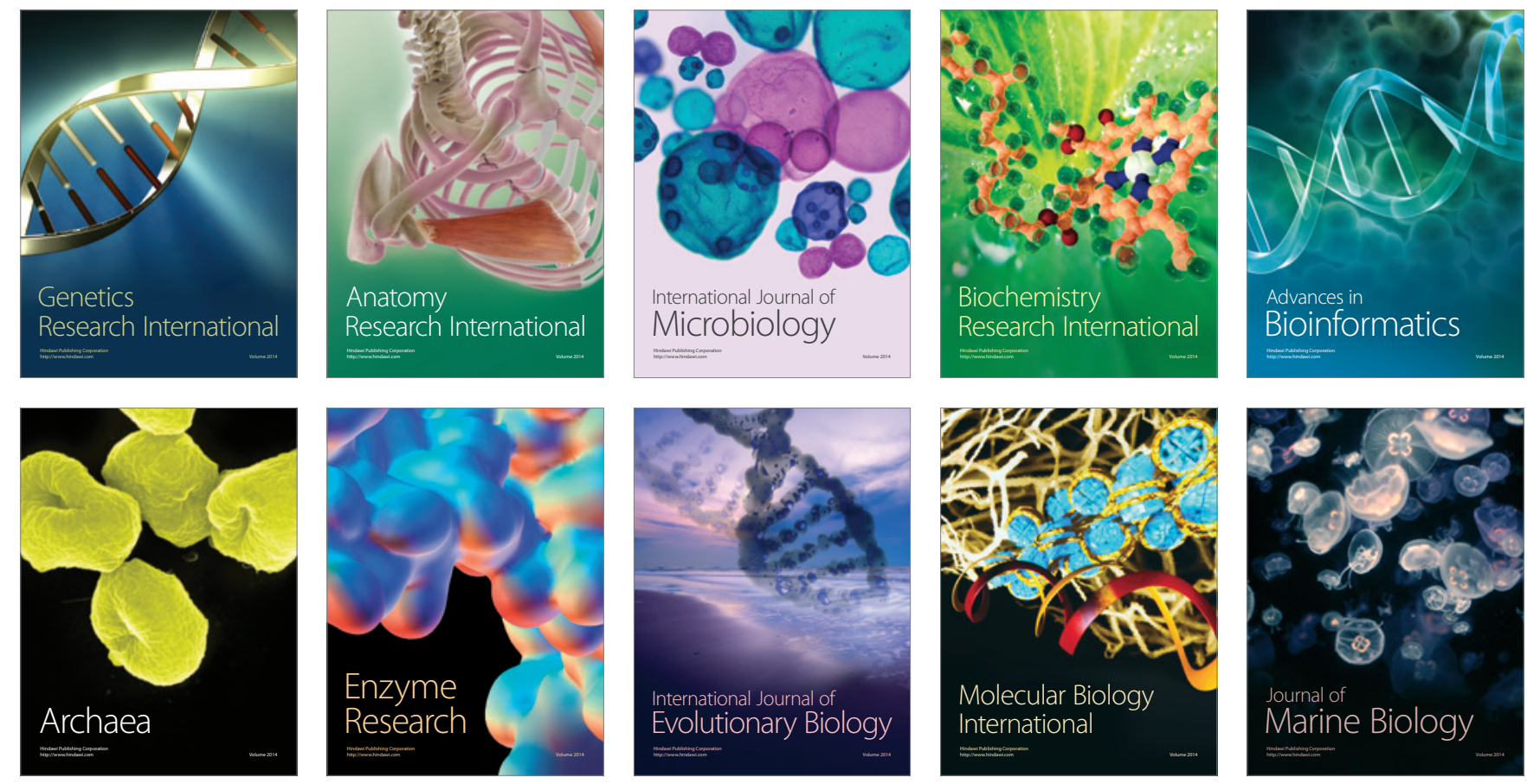